\title{
The world according to Playmobil
}

\author{
THEO VAN LEEUWEN
}

\section{Abstract}

This article looks at toys for very small children, an object of study that has been pursued in psychoanalysis (by Freud and Erikson, for example), but all too infrequently in semiotics. Specifically, it analyzes the social roles and identities called into play by the highly successful Playmobil figurines. In the Hallidayan tradition, the investigation foregrounds the importance of roles and actors in semiosis, paying close attention to roles/actors that are excluded as well as those that are included. As the essay argues, semiotic systems are always a mixture of affordance and constraint. Playmobil (in contrast to Lego, for example) is shown to be stronger on constraints than affordances, however. As a global brand and genre, the figures of Playmobil have the potential to influence nascent perceptions of the way that social actors operate.

Keywords: actor; social role; affordance; constraint; Halliday; Playmobil.

\section{Introduction}

In an earlier paper (Van Leeuwen 1996), I introduced a framework for analyzing the linguistic resources the English language has for constructing representations of the roles and identities of social actors. The categories of the framework were intended to be useful for critical discourse analysis. One part of the framework, for instance, dealt with the different ways in which social actors may either be represented as individuals (e.g., 'the alleged leader of the Sydney cell, a 40-year-old engineer') or as collectives (e.g., 'the terrorists,' or 'the cell'). The choice between 'individualization' and 'collectivization' will always be relevant for critical discourse analysis, although 'individualization' and 'collectivization' will not always mean the same thing. 'Individualization,' for instance, can be used 
to create empathy with one of the parties in a debate or conflict, or to personalize and demonize enemies.

As these categories are essentially semantic, the question arises whether they can also be realized through other semiotic modes, for instance through visual images. In a corpus of press photographs I collected during the first Gulf War, I had observed that Allied soldiers were often depicted as individuals (and named in the captions), in portraits showing them engaged in activities such as writing letters home, or carrying babies towards the safety of helicopters. Enemy soldiers, on the other hand, were usually shown in groups, often striking very similar poses, which creates the impression that 'they are all the same.' Exploring this in a later article (2000) I was able to show which ways of representing social actors can be realized both visually and verbally, which only verbally and which only visually.

The current paper continues this line of inquiry by looking at toys (more specifically dolls and figurines) as a semiotic resource for representing social roles and identities in play. ${ }^{1}$ Playmobil offers children many different social types, together with accessories that associate them with particular activities. In this paper I will investigate the way 'Preschool Playmobil' structures the social world for very young children. Which roles and identities are included? Which excluded? As we will see, toys, too, deserve the attention of critical discourse analysts. Playmobil offers quite specific perspectives on race and gender, for instance.

I will begin with an overview of the kinds of roles, identities, and meanings that dolls and figurines can convey, based, for the most part, on the three main categories of dolls included in the 'Toys as communication' research program ${ }^{1}$ : display dolls such as Barbies, Sindies, and Action Men (cf. Caldas-Coulthard and Van Leeuwen 2002), Teddy bears (cf. CaldasCoulthard and Van Leeuwen 2003), and Playmobil figures. The toys used as examples were collected in 1998 and 1999. The second part of the paper deals more specifically with Preschool Playmobil, analyzing the full range of 20 boxes with their 40 characters and 102 accessories.

Elsewhere (Van Leeuwen, 2005: 3) I have argued that social semioticians do three kinds of things:

1. collect, document, and systematically catalogue semiotic resources (including their history)

2. investigate how these resources are used in specific historical, cultural, and institutional contexts, and how people talk about them in these contexts - plan them teach them, justify them, critique them, etc.

3 . contribute to the discovery and development of new semiotic resources and new ways of using existing semiotic resources. 
This article focuses for the most part on the structure of Playmobil as a semiotic resource, on what is and what is not included in Playmobil, and on the way Playmobil characters and accessories are designed and marketed to communicate a particular perspective on the social world. But toys are designed for play, and playing can be seen as a - very visible - way of 'reading' that message, of inflecting it according to the needs and interest of the situation and of the individual child. For this reason, we have also video-recorded children at play with Playmobil, in two settings, playschool and home. ${ }^{2}$ Although a full analysis of this material will have to wait for another occasion, the final section of the paper will nevertheless include some of it, to show that Playmobil is not always 'read' as it was designed to be read, that what children actually do with Playmobil is by no means fully determined by its design, but also by contextual rules, and by the specific needs and interests of specific, individual children within that context. This will bring out two important dimensions of social semiotics (cf. Kress and Van Leeuwen 1996: 5-12; Van Leeuwen 2005: 47-69). First, the rules that connect signifiers and signifieds, and the rules that connect signs together into utterances, are social rules, rules made by people to regulate semiotic production and interpretation according to contextually specific needs and interests. Second, semiotic production and interpretation are multimodal. Although Playmobil is a distinct 'system,' in children's play it will be freely mixed with other toys and other toy systems (and with speech and gesture) - unless there are specific contextual rules prohibiting this, as in the playschool where we filmed, where small groups of children, seated around an 'activity table,' were only given one kind of Playmobil (only the pirates, or only the firemen, for instance). Yet, for all this multimodality and contingency, children will also become aware of the specific potentials and constraints of Playmobil, and indeed, of any other semiotic system. As they are playing, they will gradually learn what can and cannot easily be done and 'said' with Playmobil, of the way it bends itself easily to some meanings and resists others, of the difference between what you want to say and what Playmobil (or the adults that may regulate its use) want you to say.

\section{Roles, identities, meanings}

This section will provide an overview of the way their design can define dolls in terms of their roles, their identities, and the meanings they may, as symbolic representations, convey over and above these roles and identities. 


\subsection{Roles}

Dolls may or may not be designed kinetically; that is, they may or may not have parts that move or can be made to move by the child (Van Leeuwen and Caldas-Coulthard 2004). Such kinetically designed dolls may either be 'interactive' or 'active.' By 'interactive,' I mean here that the dolls are designed to have things done to them by the child. They are not in the first place designed to be made to interact with other dolls in representational play, they are designed to interact with the child directly, whether in role play or otherwise. Teddy bears, for instance, have a cuddly fur to allow the child to cuddle and stroke them. Other dolls, too, may have specific interactive design features - clothes that can be taken off, hair that can be combed, a mouth that takes a baby's bottle. Rag dolls, too, are interactive in this way - their extreme flexibility makes it possible to do all kinds of things to them or with them. Tamagochi dolls are another example.

In other cases, the doll is kinetically designed for representational play, designed to allow the child to make the doll do specific things or assume specific poses. I will say that a doll is kinetically designed as an 'actor' if its design allows the child to make that doll perform one or more autonomous actions, e.g., an Action Man who can throw a hand grenade, a wind-up doll who can play the drums, a baby doll who can cry, a Sindy who can swim in the bath. Such actions may be hand-driven, as, e.g., in the case of glove puppets, or powered in some way, as in the case of the hand grenade throwing Action Man and the swimming Sindy, who have elastic bands in their joints that can be 'wound up' by rotating their arms and/or legs. I will say that a doll is kinetically designed as a 'model' if its design allows the child to make it assume a range of poses, through articulated or flexible limbs, as in the case of display dolls such as Barbies. Clearly a doll can have both active and interactive features. Many teddy bears (but not all) have fairly rigid but articulated limbs (like baby dolls) but are also made of soft, cuddly material (unlike most baby dolls). The terms we introduce here index elements of design that can combine in various ways, rather than unique classifications. It should also be remembered that children can (and do) make dolls move in certain ways even when they have not been designed to do so. They can make totally rigid dolls walk, fly, swim, and so on. Yet, even when their play does not follow the scenario that has been built into the doll, children will register that what they are doing is not what the doll was made for, and in the process they will, in a very tactile way, come to understand the differences between different roles, the differences, for instance, between what Halliday (1994) calls the 'initiator' in a causative construction (the 'puppeteer' 
who makes others, in this case, dolls, do things) and the 'actor' who does things him- or herself, or the difference between actions that affect the material world and encounter its resistances (swimming, throwing hand grenades, etc.) and 'behaviors' that do not (e.g., Barbie's coy, or Action Man's threatening poses).

\subsection{Identity}

Dolls only have a specific, individual identity when they are, intentionally, given unique facial features, and this is normally only the case with hand-made dolls, e.g., many nineteenth century porcelain and wax dolls, expensive 'art' dolls and home-made dolls. Most dolls are 'generic,' whether as a result of the standard 'patterns' used to make hand-made dolls or as a result of mass production. Most dolls are also nameless generic characters, standard types, identifiable only in terms of their function or class, designed to represent categories such as 'baby,' 'black,' 'fireman,' etc., as in the case of Playmobil. Children may of course give names to 'nameless' dolls - the point here is, however, that a specific or named identity is not part of either the doll's design or its marketing. If dolls do come with names, they have the names of standard characters or types (Punch and Judy, Barbie and Ken) or of individual fictional characters (e.g., Paddington Bear) who have become types through mass production and distribution (so that it has become possible to speak of ' $a$ ' Paddington Bear). There are also 'families' of dolls, for instance in the case of teddy bears (you can have, in order of genericity, 'bear,' 'teddy bear,' 'Pooh Bear'). Special collectors' Barbies include many characters that are neither Barbie nor Ken, but still have the typical 'Barbie' size and build, for instance 'Professor Higgins.' This is not the same thing as 'collectivization' (see below), as they are not necessarily designed to be played with together, or sold as sets. The iconography of dolls as a medium of representing the world is clearly every bit as complex as the iconography of Renaissance art (cf., e.g., Hermeren, 1969: ch. 2).

There are two other key identity features. The first relates to an issue I have already mentioned, individuality versus collectivity. A doll can be designed and marketed as a stand-alone, an individual, or as a 'collectivity,' a set, intended to be played with as such, e.g., a Playmobil family or a set of tin soldiers. Here the identity of the doll derives from its membership of a group and is signified by shared physical and/or cultural attributes. A set may also be dyadic, including just two dolls, e.g., a couple such as Barbie and Ken. This is again realised by shared and complementary physical and/or cultural attributes, by making matching or 
complementary outfits available (e.g. matching beach outfits for Ken and Barbie), and by marketing them as a dyad. It signifies that their identity is to be taken as at least in part deriving from their membership of the dyad.

If we compare these elements of identity with their counterparts in language, an important difference emerges. In language, naming is not uniquely associated with the generic. It provides resources for designating things as either specific or generic, and as either individual or collective. In the case of toys - at least as they are designed and marketed - the distinction between the unique individual and the mass-produced specimen is blurred, and the child must create the doll's individuality him- or herself. As a result the question of individual identity plays a significant role in many children's stories featuring dolls and teddy bears. In a typical plot, the mass-produced toy acquires a unique identity either through wear and tear or as the result of a mistake during production. In My Old Teddy (Mansell 1991), for instance, the protagonist's teddy first loses a leg, which is then repaired by her mother. Next, her brother rips off an arm, and again it is repaired. Next, an ear comes off as a result of rough play, and again it is repaired. But when finally the head comes off, the mother declares that teddy 'has had enough' and gives her daughter a new teddy. But, says the daughter, 'I love poor old Teddy best' - it is of course precisely his unique appearance, by now covered in stitches, patches, and sticky plasters, that makes 'Old Teddy' so unique, individual, and lovable. Ruby (Glen 1997) begins with a scene in a factory where 'Mrs Harris had been day-dreaming when she made Ruby.' As a result, Ruby accidentally acquires a spotted belly and a nose which is sewn on in a crooked way. After various misadventures, Ruby ends up in a second hand store where she is picked out by Susie for her individuality (Glen 1997: 31): 'That's the one,' said the little girl. 'Yes, Susie,' said Grandfather, 'that one looks very special.'

Finally, I will say that the identity of a doll is 'physical' if it is signified by means of physical attributes such as, typically, build, facial features, skin color, and color and type of hair, or more generally, features that cannot be changed, for in the world of dolls items of dress can become fixed, quasi-physical attributes. I will say that the identity of a doll is 'cultural' if it is signified by means of cultural attributes (typically dress, hairdo, etc.), or more generally, by attributes that can be changed. In the world of dolls, what is 'physical' and immutable, and what 'cultural' and transformable, can be articulated in complex ways. The gender of a baby doll, for instance, may be signified as 'physical' if the doll has genitals (as some do) or as 'cultural' if the doll can be dressed either as a girl or a boy, but has no physical gender features. 


\subsection{Meaning}

So far I have discussed dolls that are designed to represent 'realistic' social roles and identities. Other dolls represent exaggerated characters or introduce an element of fantasy. The traits that make them unrealistic then provide clues to their symbolic meaning (cf Van Leeuwen 2001).

Sometimes a doll fuses two distinct identities. The typical teddy bear, for instance, fuses an animal (because of the fur and the snout, and sometimes the short tail) and a very young child (because of the proportions of the body). This kind of fusion corresponds to Freud's category of 'condensation' and, in good Freudian fashion, conveys a culturally 'repressed' message about the nature of the child, based on the ambivalent feelings we may have about children as being on the one hand already human, on the other hand still 'wild' and in need of being 'tamed,' 'civilized,' on the one hand 'innocent' and on the other hand 'dangerous' (in horror films the 'demonic' child is a recurring type). It may also be that the iden-

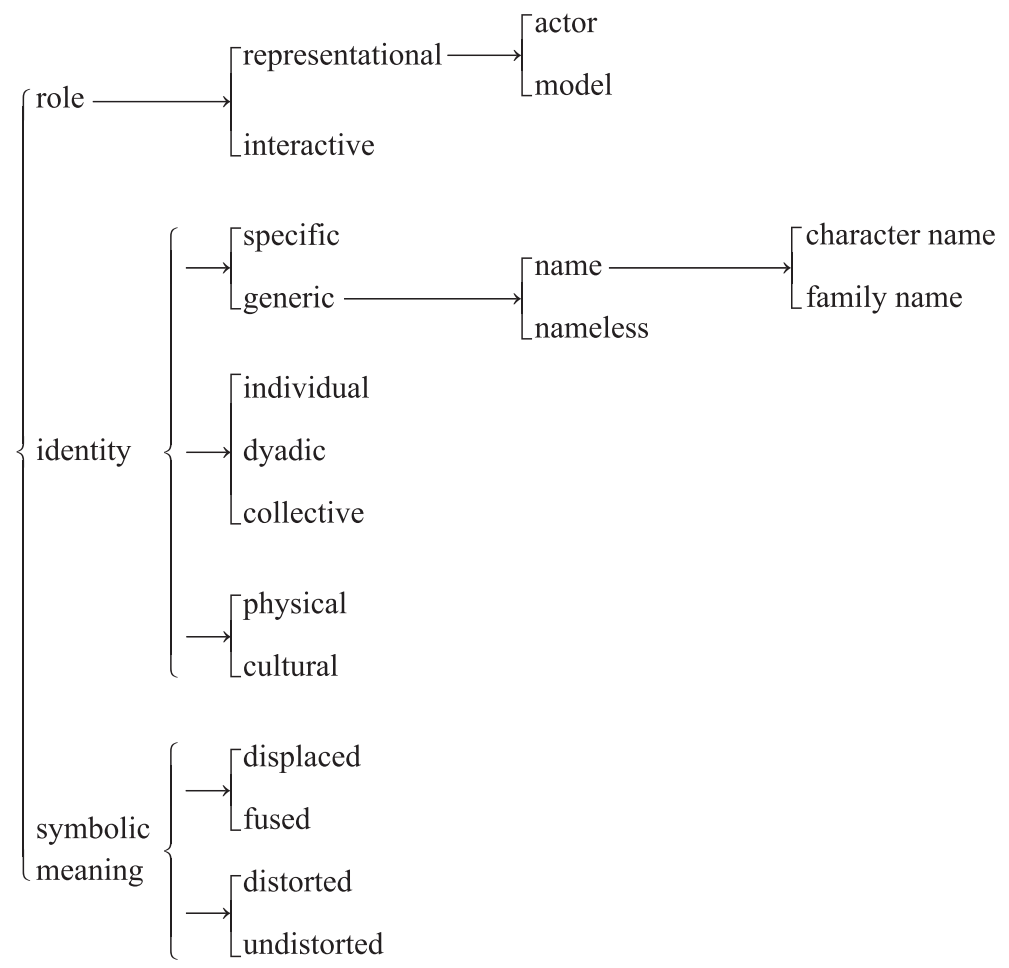

Figure 1. Representing social actors with toys - system network 
tity of a doll is set both in the real contemporary world and in either a temporally distant or mythical world - in the case of dolls, these two are not always easily separated, regardless of whether it concerns the idyllic world of the Victorian childhood or some future world of superheroes, monsters, and aliens. This corresponds to Freud's category of 'displacement.' The Barbie catalogue includes several examples. In each case a thoroughly contemporary body combines with 'period' or 'mythical' dress (e.g., the already mentioned 'Professor Higgins' Barbie, or Barbie-asCinderella), and so further inflects the multiple-layered 'character' of Barbie.

Finally, certain features of a character may be represented as excessively small or large, whether for comic effect or for other, more 'fetishistic' reasons (large breasts and muscles in characters from recent computer games).

The categories introduced above are summarized in the network above (figure 1). This network can be used as a tool for critical discourse analysis, to generate questions about how dolls represent the social world, for instance: "(When) is gender treated as a "physical," when as a "cultural" category?' 'How often are female dolls "actors" as opposed to "models"? 'What individualized black dolls are there?' 'What are the main themes in anthropomorphic animal or personified machines (e.g., Thomas the Tank engine)?'

\section{Preschool Playmobil}

In this section, I will use the framework introduced above to discuss some of the key characteristics of Preschool Playmobil, or 1.2.3 Playmobil, as it is called by the manufacturer.

\subsection{Models}

Preschool Playmobil characters are primarily designed as miniature 'models,' that is, they are designed to allow children to 'pose' them by using their articulated limbs. The options are fairly limited. They characters can either stand or sit and they can also look at things (by turning the head). This means they are capable only of 'behavioral,' non-transactive action. They cannot hold objects like Playmobil characters for older children. This is also evident from the pictures on the packaging and in the catalogues. Even if a Preschool Playmobil character is shown, e.g., in the driver's seat of a car, it is not shown as actually driving the car, but as 


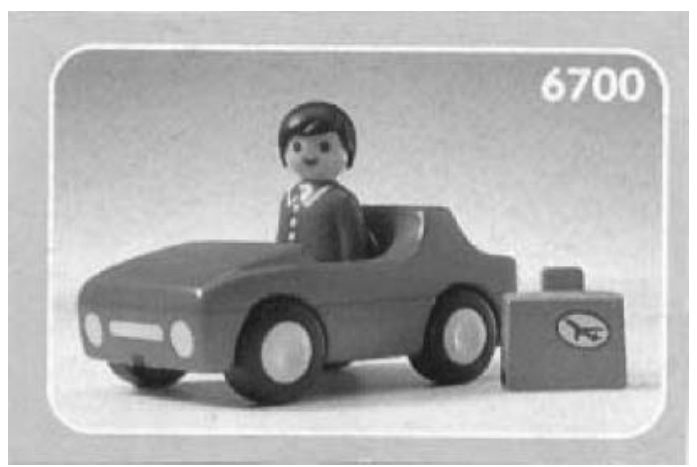

Figure 2. 'Father'

sitting in the car and looking at the viewer, as 'posing' rather than as 'doing' (figure 2). This is not the case with the packaging and the catalogue pictures of Playmobil for older children.

This also means that Preschool Playmobil characters are not 'interactive' in the sense that they can be 'dressed' or 'undressed' (e.g., by removing a helmet). There are, of course, reasons of safety behind this. Small parts can be dangerous for very young children. Preschool Playmobil figures are also somewhat larger than Playmobil characters for older children. Yet, the message will also get across that helmets, grey hair, farmer's caps, women's long hair, and so on are basic attributes, indelible, fixed characteristics of specific social types.

\subsection{Individuality}

Preschool Playmobil characters may be individually or collectively identified. This depends on the way they are packaged as individuals or groups. Here are some of the groups: the 'ethnic family,' the 'family,' a mother, daughter and baby (in a bathroom box, cat. Nr. 6614), and a grandfather, grandmother, and cat (figure 3 ).

Couples include a male and female horse rider, the farmer and his wife, and the grandparents. Clearly, family identity plays an important role in Preschool Playmobil. There are fathers, mothers, brothers, sisters, babies, grandfathers, grandmothers, and pets (taken separately these can become men, women, boys, girls, babies, old men, old women). Yet some family members, here the 'father' and the 'grandparents,' are also separately marketed and therefore also have an identity that is separate from the family (figure 4). 


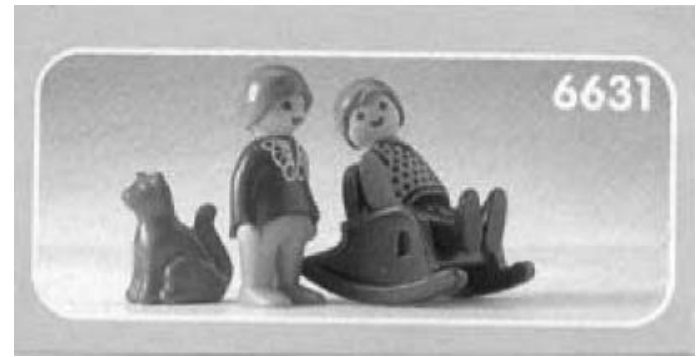

Figure 3. 'Grandparents'

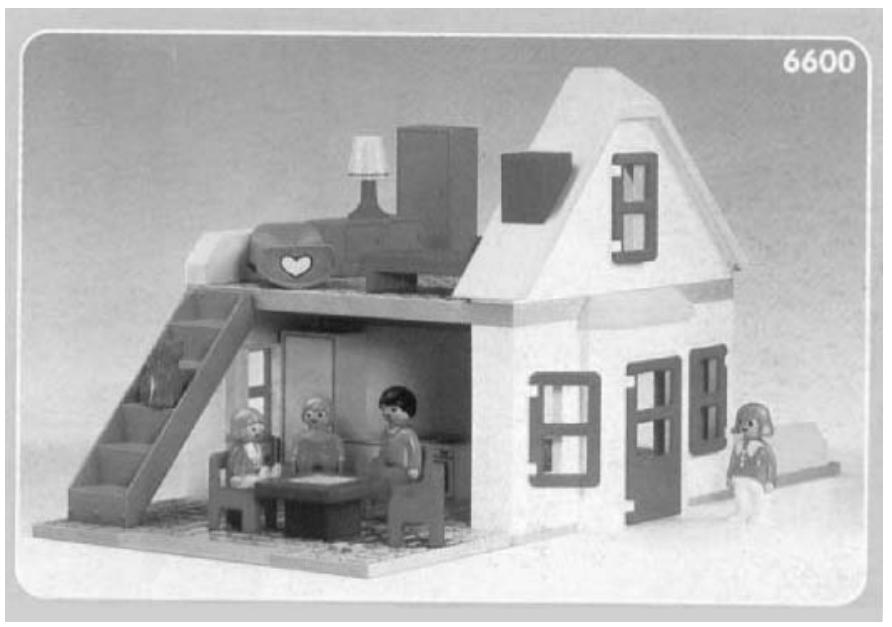

Figure 4. 'Family'

In other words, family identity is relational, deriving from your relations with others, and also some members, most notably the father (figure 2 ) and the grandparents also have an identity that is separate from that.

\subsection{Social types}

Preschool Playmobil characters are also nameless and generic, social types, even in their identities as fathers, mothers, brothers, sisters, and so on, and they represent the social world with a certain conceptual realism (cf. Kress and Van Leeuwen 1996). There are, in Preschool Playmobil, no characters drawn from fiction, no anthropomorphic animals or aliens, 
and the cars and houses are resolutely contemporary, without any fantasy, anachronistic or futuristic features. Playmobil for older children, however, does have fantasy characters, historical characters, aliens, and so on, increasingly so. It is as if a solid foundation of close-to-home reality must be laid before the world of pirates, fairytale princesses, wizards, witches, and Wild West characters can be entered. Yet the everyday world of Preschool Playmobil is conceptual. It does not realistically reproduce what is out there in the world, as in the case, for instance, of matchbox miniature cars. There is, in this world, only one kind of car, the basic car (figure 2), a car which has the minimum features any car must have to be able to be recognized as a car, no more and no less.

What makes people into types in this world? Essentially four things: professional and leisure activities, gender, race, and age. All of these elements of identity are signified by specific simple identity-marking attributes (the road worker's truck and danger sign, the policeman's traffic light and car, and so on) - and, in the world of Preschool Playmobil no difference exists, as yet, between 'leisure activities' such a horse riding, and professions. Another category runs across these three, the category of social class. There are three social classes, each with a distinct, recognizable key attribute. Professions with high rank status are signified by a uniform with a cap that bears the insignia of their rank, e.g., a captain or a policeman (figure 5).

High-ranking professions or roles have a helmet and a uniform, e.g., horse riders, firemen, and lower ranking occupations wear overalls and a cap without insignia, e.g., a tow truck driver or a road worker (figure 6).

Some intermediate forms exist, for instance the ambulance driver, who has no cap but also does not wear overalls. In other words, the key dis-

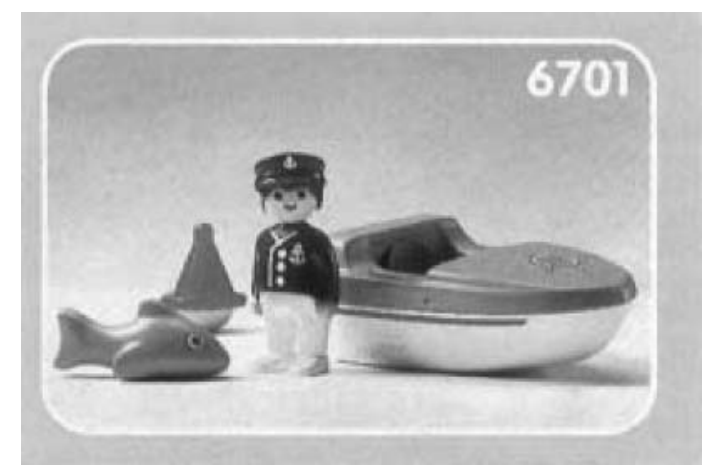

Figure 5. 'Captain' 


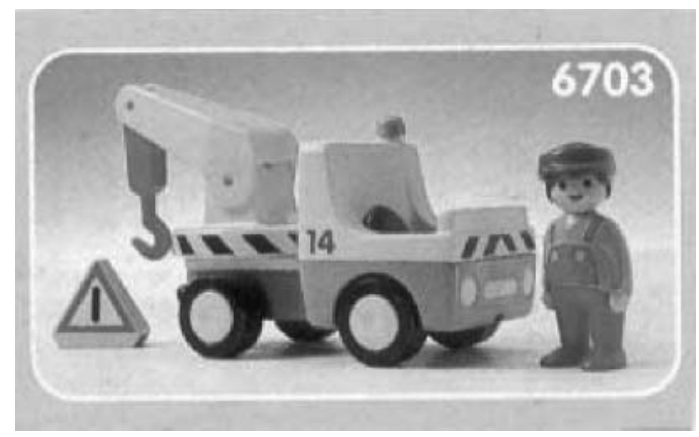

Figure 6. 'Road worker'

tinctions here are those of rank (caps with or without visor and with or without insignia, and status with or without overalls). The identity of the road worker, therefore, is determined both by the activity in which he engages, as signified by his truck and danger sign, and by his class, as signified by his dress.

Gender is signified by a small vocabulary of variations in hair style. Adult women either have long hair which bobs out on the side or wear their hair in a bun. Older women and black women wear their hair in a bun, younger, white women do not. As a result, older women and black women lack a feature of 'female attractiveness.' Color and style of dress does not strongly differentiate between male and female, but there is a sharp distinction between male and female activities. The baby, finally, can only sit and has a 'male' hair style.

Race is signified by the color of skin and hair - brown skin, black hair. It can be noted that in the group marketed as 'the family' (figure 4) the different family members (mother, father, son, daughter) have different hair colors, whereas all members of the 'ethnic family' (figure 7) have

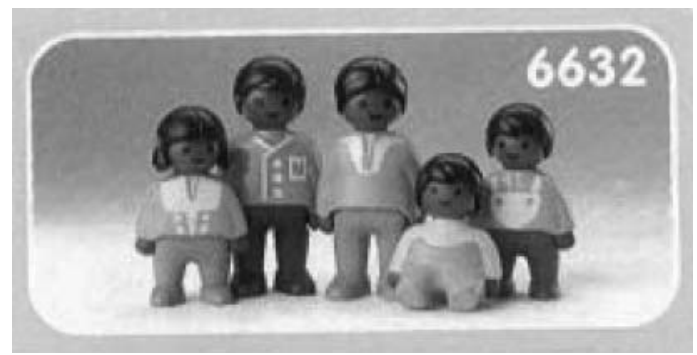

Figure 7. 'Ethnic family' 
the same hair color. The individuality of the members of this family is therefore less marked. They also have more children than the family in figure 4.

Old age (cf. figure 3) is signified both by 'physical' attributes (grey hair) and 'cultural' attributes (brown and grey clothes with painted on motifs and textures, e.g., a woollen cardigan for the grandfather).

\subsection{Activities}

Playmobil characters are packaged with accessories that suggest preferred activities. Through these accessories, they are defined, not just by their 'physical' and 'cultural' attributes, but also by their activities. There is only one exception to this. In the 'ethnic family,' neither the family, nor its individual members are accompanied by any accessories such as a house, furniture, a car, tools, etc.

The accessories of the grandparents (or old people generally) speak for themselves (rocking chair, lounge suite, cosy stove, chess table, large cupboard, clock, table, light) as do the accessories of the (white) family, as ordered by the layout of their house - kitchen: dining table, stove, dishwasher, cupboard; bedroom: bed, cot, sideboard, baby's dressing table; exterior: car, boat on trailer, trees; bathroom (female family members only): bath, mirror, shower, toilet, washbasin.

Apart from being almost exclusively male, professional activities are dominated by mobility. The father (available as part of the family box, but also, and as the only member of his family, separately, with car): car, suitcase with airplane label. The policeman: car, traffic light. The ambulance man: ambulance. The fireman: fire truck, danger sign. The pilot: plane, wind vane; The tow truck operator: tow truck, danger sign. The road worker: truck, danger sign. The captain: boat, fish, buoy. The farmer: tractor and trailer, cow, pig, bag of wheat. The horse riders: horses, hurdles, bushes.

The only characters whose accessories do not involve mobility are the old man (rocking chair), the shepherd (pen with sheep, dog, some trees), and the farmer and his wife as a couple (pigs, cows, feeding trough, dog, bag of wheat). Separately, however, the farmer has a tractor and trailer. Mobility is therefore signified as exclusively male, with the single exception of the female horse rider.

I hope this brief analysis of Preschool Playmobil (as it was in 1999) has demonstrated that the way in which this toy system is designed and marketed provides a model of society, structured by organizing principles such as work and leisure, age, gender, ethnicity and class, and by the dif- 
ference between the private and the public world, and marking all these social categories with clear, visible attributes. I will now conclude with some observations of the way this model is used in play.

\section{Playing with Playmobil}

As part of this study of Playmobil, video recordings were made of 2 to 4-year-old children playing with Playmobil in a preschool in Birmingham. ${ }^{2}$ During the filming the researcher sat on the floor with the children, letting the play episodes develop, but occasionally intervening to ask the children to identify specific characters. This did not appear to disturb the children or interrupt the flow of the play, and yielded additional data, as can be seen in the transcript below. The playschool imposed specific rules on the children's play. All children were seated, in groups of six, around 'activity tables.' One of these activity tables was devoted to Playmobil, but only of one kind, in this case firemen (this set is in fact a set for older children, rather than part of the Preschool Playmobil range). The interaction was at times quite chaotic, with several conversations and actions happening at the same time, and the children often snatched characters or accessories from each other, without being overly disturbed by this. As we start, the researcher places the firemen set on the table. It includes ladders and other fire brigade implements such as a mattress (for people trapped in a building to jump on) and a spade (to throw sand on a fire). In the transcript I focus on Page (two and a half years old), without transcribing all the simultaneous actions and utterances of the other children.

Page grabs a fireman in each hand

Researcher: Who's that?

Page: He's a fireman!

She drops one of the firemen and tries to fit a hat on the other one, but fails to do so. After a while she gives up and picks up a ladder.

Page: Ladder! Ladder!

She puts the ladder down and grabs the mattress, then looks around, as if searching for something quite specific among the toys on the table. The boy next to her, who has been trying to make a fireman climb a ladder, puts his ladder on Page's mattress. When he is momentarily distracted, she grabs the mattress for herself again and lays the fireman on it, using the mattress as a bed.

Researcher: Who is that?

Page: It's a baby. 
The researcher points at the two firemen Page is holding in her right hand.

Researcher: And that one, who is that one?

Page: This is Mama, look.

Researcher: And who is that one?

Page: It's Daddy.

Page looks at the toys again, grabs the spade and starts using it as a spoon to feed the 'fireman-baby' on the mattress.

Already Page can recognize a fireman. Maybe she has been read books about firemen. Firemen are after all recurrent figures in books for very young children. But she can recognize other characteristics of the fireman as well, for instance that he is very small, especially in comparison to the mattress. He could also be a baby. So she uses the fireman, the mattress and the spade, not to enact a heroic rescue, but interactively, to act out a mother and baby scenario in which she plays the role of the mother.

Kieran (four years old) was given a much wider range of Playmobil toys at home. It included some Preschool Playmobil characters and accessories as well as ones from sets for older children. He was filmed by his father. The researcher was sitting on the floor next to him. We had included the 'ethnic family' because Kieran is black, but he did not use any of the members of the 'ethnic family.' As the episode starts, Kieran is trying to open a plastic bag.

Researcher: I'll open it for you ... There you go

She hands the content of the bag to Kieran - a bike and a bike rider. Kieran takes it and smiles

Kieran: Who is riding on the bike now? Who is riding on the bike?

Researcher: This is the biker

Kieran tries to put the biker onto the bike for a brief moment, but then throws him back on the pile of Playmobil toys and surveys the toys, his hands folded in front of his face, almost as if praying. After a while he picks up another Playmobil character. It is a wizard with a long pointed beard.

Kieran: This is the biker.

He tries to put the wizard on the bike, but as he has not been designed to sit on a bike, he does not fit. Kieran keeps trying, increasingly frustrated, and then hands the bike and the biker to the researcher

Kieran: Can you help me?

The researcher tries for a moment

Researcher: Perhaps it's not the biker. 
She puts the wizard down, picks up the actual biker, puts him on and hands biker and bike to Kieran. Kieran looks at it for a while, then puts it down, and picks up another Playmobil figure. He is not smiling anymore and he has lost interest in the bike and the biker

Kieran: This is a little baby.

Clearly, Kieran wanted to create a character who does not feature in the ordered world of Playmobil. He associated the bike, not with a neatly helmeted, non-descript rider, but with a biker. The straggly beard and unkempt appearance of the wizard were close enough for him. But this was something you cannot 'say' in the language of Playmobil, an 'ungrammatical' statement. The wizard was not designed to slot onto the motorbike. The researcher could not help him and in fact suggested the 'proper' solution, but Kieran had already lost interest, giving up on the idea of a wild biker and turning to a little baby instead.

It would be easy to argue, on the basis of the first example, for the infinite malleability of Playmobil as a resource. Playmobil did not force Page into narrowly defined roles and interactions. It turned out to be usable, not just as a resource for representational play, it could also be used interactively. It would also be easy to overstate the other case, the constraints imposed by the system, the way it does not allow 'deviant' meanings. Semiotic systems are always a mixture of affordance and constraint, already in childhood. Yet some are more flexible than others. Construction toys such as Lego in its original form offered few constraints, and allowed children to build a wide range of things. Today's young children, sitting at the computer, too often must learn to follow the sometimes quite inflexible trajectories that designers have programmed for them, and, despite all the talk of choice, may live in a much more bony-structured world than their parents did when they were children.

\section{Notes}

1. The research for this paper was part of a research program 'Toys as Communication,' led by Professor Staffan Selander of the Institute of Education, Stockholm and financed by a grant from the Swedish Royal Bank.

2. Videos of children playing with Playmobil in a Birmingham playschool and in their home settings were recorded by Dr. Carmen Caldas-Coulthard.

\section{References}

Caldas-Coulthard, C. R. and Van Leeuwen, T. (2002). Stunning, shimmering, iridescent: Toys as the representation of gendered social actors. In Gender Identity and Discourse Analysis, J. Sunderland and L. Litosseliti (eds.), 91-110. Amsterdam: Benjamins. 
Caldas-Coulthard, C. R. and Van Leeuwen, T. (2003). Teddy bear stories. Social Semiotics 13 (1), 5-29.

Glen, M. (1997). Ruby. In The Hutchinson Treasury of Teddy Bear Tales, S. Gretz (ed.), 2434. London: Hutchinson.

Halliday, M. A. K. (1994). An Introduction to Functional Grammar, 2nd ed. London: Arnold.

Hermeren, G. (1969). Representation and Meaning in the Visual Arts. Lund: Scandinavian University.

Kress, G. and Van Leeuwen, T. (1996). Reading Images: The Grammar of Visual Design. London: Routledge.

Mansell, D. (1991). My Old Teddy. London: Walker.

Van Leeuwen, T. (1996). The representation of social actors. In Texts and Practices: Readings in Critical Discourse Analysis, C. R. Caldas-Coulthard and M. Coulthard (eds.), 3270. London, Routledge.

Van Leeuwen, T. (2000). Visual racism. In The Semiotics of Racism: Approaches in Critical Dicsourse Analysis, M. Reisigl and R. Wodak (eds.), 333-350. Vienna: Passagen Verlag.

Van Leeuwen, T. (2001). Semiotics and iconography. In Handbook of Visual Analysis, T. van Leeuwen and C. Jewitt (eds.), 92-118. London: Sage.

Van Leeuwen, T. (2005). Introducing Social Semiotics. London: Routledge.

Van Leeuwen, T. and Caldas-Coulthard, C. R. (2004). The semiotics of kinetic design. In Text and Texture: Systemic Functional Viewpoints on the Nature and Structure of Text, D. Banks (ed.), 356-381. Paris: L'Harmattan.

Theo Van Leeuwen (b. 1947) is a professor at the University of Technology in Sydney 〈theo. vanleeuwen@uts.edu.au $\rangle$. His research interests include social semiotics, multimodality, and critical discourse analysis. His major publications include Reading Images: The Grammar of Visual Design (with Gunther Kress, 1996); Speech, Music, Sound (1999); Introducing Social Semiotics (2005); and Discourse and Practice: New Tools for Critical Discourse Analysis (2008). 